\title{
Production of a SCID mouse model of medulloblastoma to explore the therapeutic value of targeting tumor driver genes
}

\author{
YONG HAN, MIN CHEN and HANGZHOU WANG \\ Department of Neurosurgery, Children's Hospital of Soochow University, Suzhou, Jiangsu 215000, P.R. China
}

Received June 26, 2019; Accepted October 20, 2020

DOI: $10.3892 / \mathrm{etm} .2020 .9540$

\begin{abstract}
Tumor driver genes are genes where structural or sequence mutations confer a selective advantage for cancer cells. The individualized targeting of tumor driver genes has become a topic of interest for tumor treatment. The prognosis for medulloblastoma (MB), a common type of malignant intracranial tumor found in children, is poor. The tumor driver genes and the corresponding targeted drugs remain to be studied. The present study analyzed tumor driver genes from tumor tissue and peripheral blood from one patient with nodular desmoplastic MB with Sonic Hedgehog activation and screened targeted drugs for the tumor driver genes. Additionally, MB tissue was successfully implanted into the SCID mouse which were then used for subsequent drug screening. The present study explored novel treatments for MB from the perspective of tumor driver genes, and may provide new ideas for choosing individualized targeted therapies for patients with MB.
\end{abstract}

\section{Introduction}

Medulloblastoma (MB) is a small round blue cell tumor of the cerebellum and is one of the most common types of malignant brain tumors presented during childhood (1). MB is classified based on the histological features into three major forms of the disease: Classic, nodular/desmoplastic (ND) and large cell/anaplastic (2). With recent advances in genomics, gene expression profiling and DNA methylation analysis, $\mathrm{MB}$ has been further divided into four major subgroups: WNT/Wingless, Sonic Hedgehog (SHH), Group 3, and Group $4(3,4)$. The overall survival rates range from $60-80 \%$ (3). Current treatments for MB include surgical resection, cranio-spinal radiation (for children older than 3 years) and chemotherapy; however, long-term survivors of MB will face significant treatment-related morbidity secondary to the current treatments (4-6). The significant complications and

Correspondence to: Dr Hangzhou Wang, Department of Neurosurgery, Children's Hospital of Soochow University, 92 Zhongnan Street, Suzhou, Jiangsu 215000, P.R. China

E-mail: 13771843695@163.com

Key words: medulloblastoma, tumor driver gene, targeted drugs reduced quality of life caused by conventional treatments remain an issue which need to be addressed. As such, there has been much research interest aimed at dissecting the molecular genetics underlying the disease.

Cancer is initiated and driven by aberrant genetic events, such as copy number aberrations (CNAs), also called the drivers of cancer (7). A number of cancer types, such as glioblastoma, breast cancer and MB, contain subtypes, with each subtype possessing distinct molecular profiles and clinical outcomes (8-10). In cancer research, driver genes have been defined as genes whose structural or sequence mutations will confer a selective advantage to the cancer cell $(11,12)$. A number of driver genes have been shown to have CNAs or associated changes in the gene expression profile which may cause oncogenesis (13). A previous study found that driver genes are essential in carcinogenesis and could be potential targets for cancer therapy (14). As such, the identification of tumor driver genes behind the development of MB is of great interest.

The present study tested for tumor driver genes from one patient with MB and selected their potential corresponding targeted drugs. Meanwhile, the MB tissue was successfully implanted into SCID mice which were used for subsequent drug screening.

\section{Materials and methods}

Human tissue sample. For the present study, MB tissue was obtained from a Chinese patient from the Department of Neurosurgery, Brain and Nerve Research Laboratory of The First Affiliated Hospital of Soochow University (Suzhou, China).

The patient was a 2 years and 3 months old boy in June 2015 when he went through surgery. The patient was treated at the hospital because of frequent vomiting. The preoperative examination [CT and MR (magnetic resonance)] revealed a tumor in the fourth ventricle. The tumor was removed using the suboccipital midline approach. This was his first operation. Before the operation, the patient did not receive radiotherapy or chemotherapy. The tumor specimen obtained during surgery was stored in DMEM culture medium and transported to laboratory immediately. The tumor specimen was crushed and used for implantation in SCID mice.

Statement of informed consent. The human sample was used in accordance with the policies of the institutional review board of The First Affiliated Hospital of Soochow University 
(approval no. 8187101042). The sample from the MB patient was used with the written consent of parents.

Intracranial implantedmodels. A total of 10 female and 10 male SCID mice (purchased from Shanghai Slack Laboratory Animal Co., Ltd.) which were 4-6 weeks old were used for experiments. The mice were raised in specific-pathogen free conditions and the temperature was maintained between 26 and $28^{\circ} \mathrm{C}$. The mice were exposed to $\sim 10 \mathrm{~h}$ light per day and given food and water following high-temperature sterilization. The mice were raised separately, but under the same conditions. The animals had free access to food and water (ad libitum), animal feed was nutritionally balanced. The weight of the mouse was $15-20 \mathrm{~g}$ when used for implantation. The MB tissue specimen collected from the surgery was used to make a cell suspension with a concentration of $10^{6}-5 \times 10^{7}$ cells $/ \mathrm{ml}$. Cells were grown in DMEM (Hyclone; GE Healthcare) supplemented with 10\% FBS (Gibco; Thermo Fisher Scientific, Inc.). The SCID mice were placed on a homemade intracerebral injection device after anesthesia by diazepam and chloramine intraperitoneal injection. After head skin disinfection, $0.1 \mathrm{~cm}$ right or left of the midline, $0.3 \mathrm{~cm}$ before the coronal suture, the sample trace on the device was used to penetrate the skin and skull. The depth was controlled between 1-2 mm. According to the concentration of the cell suspension, a total of 5-10 $\mu \mathrm{l}$ cell suspension was injected and the injection time was controlled to be $<15 \mathrm{~min}$. The mouse weight was measured every 2-3 days. If the mice lost $30-35 \%$ of their body weight in 3 days, or if they had a limb movement disorder, magnetic resonance (MR) examination was performed immediately to observe the intracranial tumor formation of the SCID mice. The mice were sacrificed by cervical dislocation. The cell culture medium of the same volume was injected into 10 control SCID mice using the aforementioned protocol. The study was approved by Medical Ethics Committee of Children's Hospital of Soochow University.

Subcutaneous implanted models. A total of 20 SCID mice, including 10 female mice and 10 male mice which were 4-6 weeks old were used for experiments. The weight of the mouse was 15-20 g when used for implantation. The SCID mice were placed on a homemade injection device after anesthesia by diazepam and chloramine intraperitoneal injection. A subcutaneous SCID mouse model was established using $\sim 1 \times 10^{6} \mathrm{MB}$ cells. Tumor cells were injected subcutaneously into the back of the mice. On day 14 postimplantation, the subcutaneous tumors formed in 6 mice. The mice were then sacrificed by cervical dislocation. Subcutaneous tumors were then extracted. Tumor specimens were either preserved in liquid nitrogen or in $4 \%$ paraformaldehyde for $2 \mathrm{~h}$ at $37^{\circ} \mathrm{C}$ for further experiments.

Immunohistochemistry (IHC). Tumor tissues from the patient and from the mice were prepared and fixed in $4 \%$ paraformaldehyde for $2 \mathrm{~h}$ at $37^{\circ} \mathrm{C}$. Formalin-fixed paraffin-embedded tumors were sectioned using a microtome into 6- $\mu \mathrm{m}$ sections. Antigen retrieval was performed using $10 \mathrm{mM}$ sodium citrate buffer, $\mathrm{pH} 6$, for $16 \mathrm{~min}$ at $96-98^{\circ} \mathrm{C}$. Slides were incubated with primary antibodies including Ki-67 (cat. no. BA2888; Wuhan Boster Bioengineering Co., Ltd.), GFAP (cat. no. BA2689; Wuhan Boster Bioengineering Co., Ltd.), P53 (cat. no. BA2358; Wuhan Boster Bioengineering Co., Ltd.) and Syn (Synaptophysin; cat. no. ab14692; Abcam). All primary antibodies were diluted to 1:1000 and incubated for $24 \mathrm{~h}$ at $4^{\circ} \mathrm{C}$. Sections were subsequently incubated with the Cell \& Tissue Staining kit HRP-DAB system (R\&D Systems, Inc.). The secondary antibodies (diluted to 1:200; cat. no. ab6721; Abcam) were added and incubated for $2 \mathrm{~h}$ at $37^{\circ} \mathrm{C}$, according to the manufacturer's instructions. Immunostaining was performed with known positive and negative tumor controls and were blindly evaluated by a pathologist. The percentage of positive cells was calculated by randomly selecting six sites in the histopathological section of the tumor. - was defined as no pathological sections being positive for the marker; + - was defined as the majority of the pathological sections being positive for the marker; -/+ was defined as some of the pathological sections being positive for the marker; and + was defined as all pathological sections being positive for the marker.

Detection of the tumor driver genes. The detection of tumor driver genes was performed by First Imension. The tumor specimen and peripheral blood from the patient were used for exon sequencing. The technology used in the present research was target region capture combined with second generation high-throughput sequencing. FFPE samples were extracted and sequenced using the GeneRead ${ }^{\mathrm{TM}}$ DNA FFPE kit (cat. no. 180134; Shanghai YuBo Biotechnology Co., Ltd.). Agarose gel electrophoresis was used to analyze the degree of DNA degradation and the presence of RNA and protein contamination. Qubit quantifies DNA concentrations precisely. Illumina PE150 (Pair end 150 bp) sequencing was performed according to the effective concentration and data output requirements of the library. PE150 refers to high-throughput double-end sequencing, with each end measuring $150 \mathrm{bp}$. According to the tumor driver gene results, PTCH1 and SMO were used as the key words to search on the Internet. The web site used was as follows: https://www.clinicaltrials.gov.

\section{Results}

Establishment of intracranial and subcutaneous tumor model in SCID mouse. A two-year-old patient was considered to be MB positive based on imaging data (CT and MR) taken before surgery (Fig. 1A-C). The tumor was surgically removed, with a section taken for the present study (Fig. 1D and E). The remaining section of the tumor specimen was used for pathological examination to make a definitive diagnosis. The present study used the tumor specimen for intracranial and subcutaneous implantation into SCID mice for subsequent targeted drug screening.

IHC results from the tumor sample taken from the patient were as follows: $\mathrm{Ki}-67(+)$ 80\%, GFAP(-/+) and P53(-/+) (data not shown), as well as $\operatorname{Syn}(+)$ (Fig. 2). These markers are used to identify different tumors and malignancy degree (15). $\mathrm{Ki}-67$ is a marker of cell proliferation and Syn is a classical marker for MB. According to the aforementioned IHC results, the diagnosis was ND MB with $\mathrm{SHH}$ activation. MR examination was used to observe the intracranial tumors of the SCID mouse. After one month following implantation, the 
A

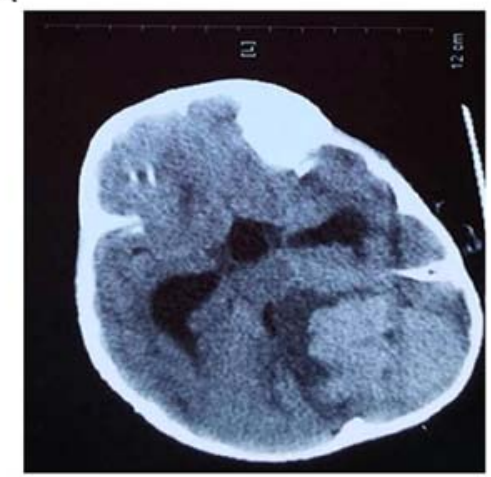

D

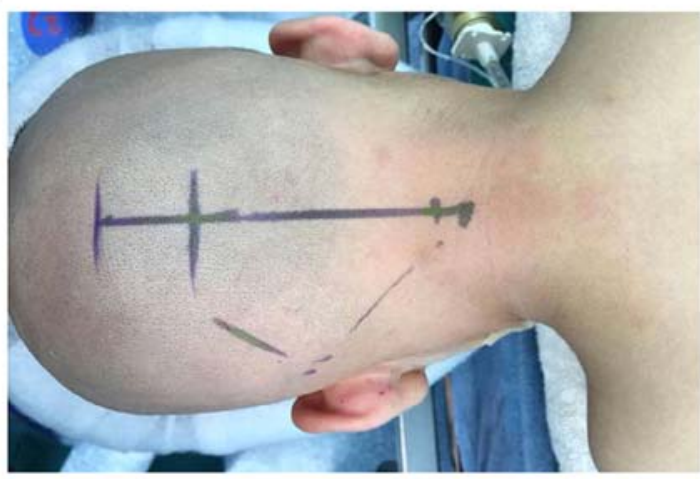

B

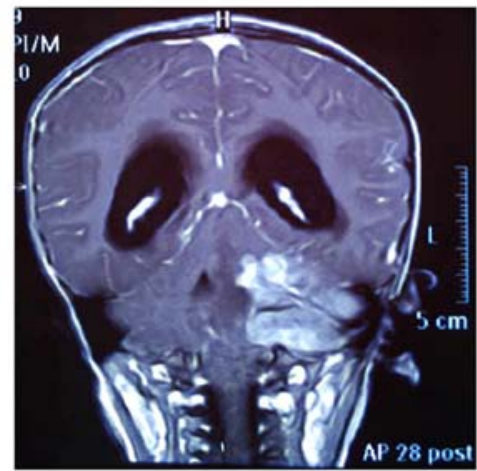

C

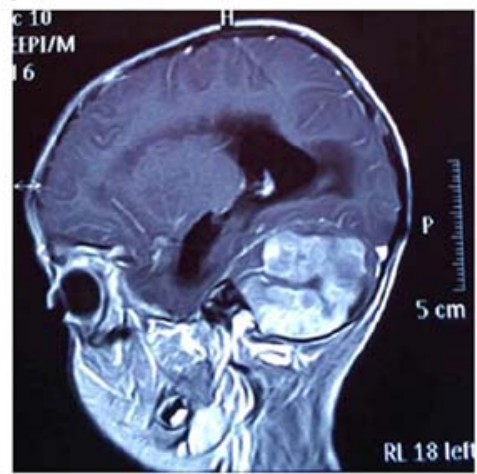

E

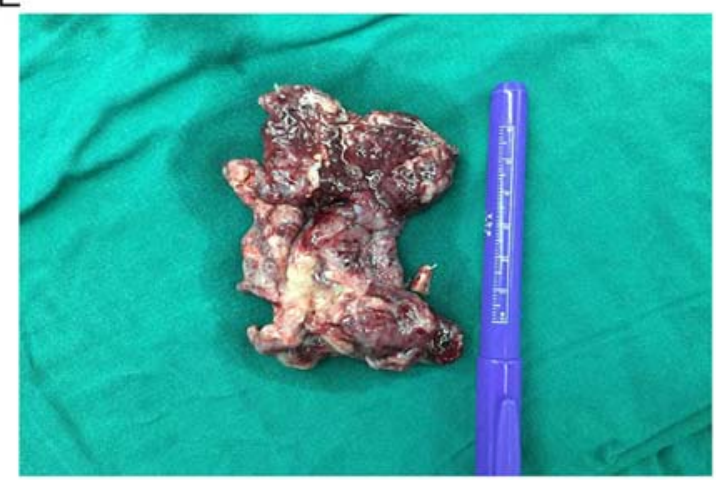

Figure 1. Images of the patient with MB. (A) Computed tomography of the patient with MB. (B) Coronal enhanced MRI demonstrated the tumor of the fourth ventricle. (C) Sagittal MRI demonstrated the tumor of the fourth ventricle. (D) Surgical incision of the MB patient. (E) The surgically removed tumor. $\mathrm{MB}$, medulloblastoma; MRI, magnetic resonance imaging.
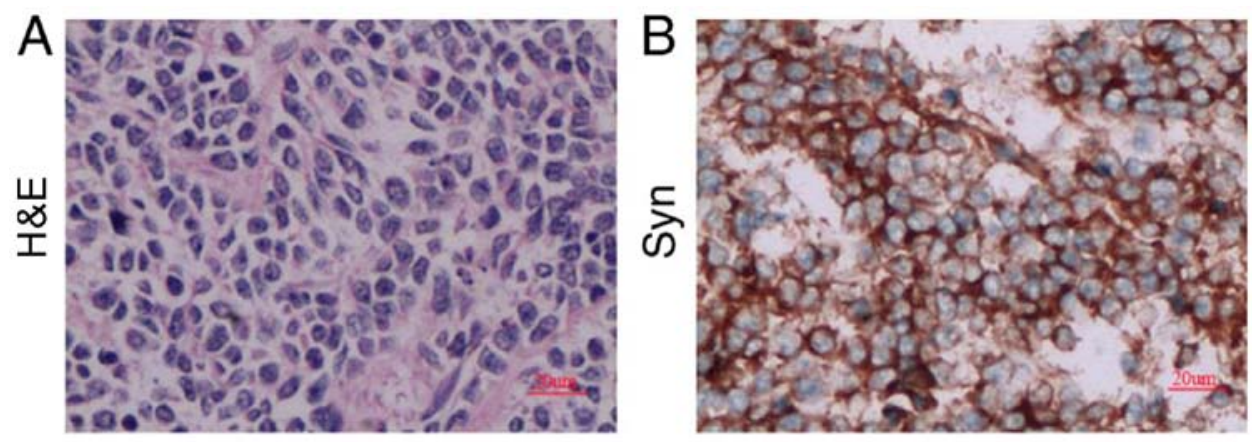

Figure 2. Pathological manifestation of the tumor specimen from the patient. (A) H\&E staining of the tumor tissue. (B) Immunohistochemistry of the tumor tissue showed Syn(+) cells in the tumor specimen. Magnification, x500. Syn, Synaptophysin.

tumor was found in the brain of the SCID mouse (Fig. 3A). Tumor formation was not observed in the brain of the control mouse (Fig. 3B, E and F). Subsequently, the tumor tissue from the SCID intracranial tumor mouse was collected and analyzed. The results were the same as that observed in the excised, unimplanted tumor tissue (Fig. 3C and D). Tumor cells from the patient were also used for subcutaneous implantation in SCID mice (Fig. 3G). Mice with subcutaneously inoculated cells developed xenograft tumors after 2 weeks, which may be used for subsequent targeted drug screening experiments.

Detection of tumor driver genes in MB. Peripheral blood and tumor specimens from the patient were used for the detection of tumor driver genes. Sequence capture technology was used to test all exons using high-throughput sequencing. The results found point mutation, deletion, insertion, copy number and structural variations. In the present study, three genetic variants were found from the samples taken from the patient with MB, including PTCH1p.F573S, PTCH1p.S574P, PTCH1p.L575P (Tables I and II).

Screening for tumor driver gene-related targeted drugs. It was found that the drugs Vismodegib and Sonidegib, which target mutations in PTCH1, have been approved by the FDA for the therapy of other types of tumors (Table III). Currently, there are no drugs for the treatment of mutations to PTCH1 in MB. The drug BMS-833923, which targets PTCH1 mutations in solid and blood tumors is still in clinical trials (Table III). 
Table I. Significant mutations of germ cells.

\begin{tabular}{|c|c|c|c|c|c|c|}
\hline Gene & $\begin{array}{l}\text { Reference } \\
\text { sequence }\end{array}$ & $\begin{array}{l}\text { Nucleotide } \\
\text { mutation }\end{array}$ & $\begin{array}{c}\text { Amino acid } \\
\text { mutation }\end{array}$ & $\begin{array}{l}\text { Cover } \\
\text { depth }\end{array}$ & $\begin{array}{l}\text { Cover depth } \\
\text { of mutation }\end{array}$ & $\begin{array}{l}\text { Frequency } \\
\text { of mutation }\end{array}$ \\
\hline BRCA2 & NM_000059 & c.T943A & p.C315S & 330 & 160 & $48 \%$ \\
\hline BRCA2 & NM_000059 & c.A10234G & p.I3412V & 241 & 122 & $51 \%$ \\
\hline PRDM1 & NM_182907 & c.C998T & p.P333L & 812 & 412 & $51 \%$ \\
\hline HEY1 & NM_001282851 & c.C50T & p.T17M & 303 & 175 & $58 \%$ \\
\hline MN1 & NM_002430 & c.T1682C & p.M561T & 289 & 138 & $48 \%$ \\
\hline
\end{tabular}

All mutations were nonsynonymous mutations. BRCA, breast cancer susceptibility gene; PRDM, PR domain containing zinc finger protein; HEY, Hes related family; MN, meningioma.

Table II. Significant mutations of somatic cells.

\begin{tabular}{lcccccc}
\hline Gene & $\begin{array}{c}\text { Reference } \\
\text { sequence }\end{array}$ & \multicolumn{1}{c}{$\begin{array}{c}\text { Mutation } \\
\text { type }\end{array}$} & $\begin{array}{c}\text { Nucleotide } \\
\text { mutation }\end{array}$ & $\begin{array}{c}\text { Amino acid } \\
\text { mutation }\end{array}$ & $\begin{array}{c}\text { Cover } \\
\text { depth }\end{array}$ & $\begin{array}{c}\text { Cover depth } \\
\text { of mutation }\end{array}$ \\
\hline PTCH1 & NM_000264 & Nonsynonymous mutation & c.T1718C & p.F573S & 44 & 40 \\
PTCH1 & NM_000264 & Nonsynonymous mutation & c.T1720C & p.S574P & 44 & 40 \\
PTCH1 & NM_000264 & Nonsynonymous mutation & T1724C & p.L575P & 44 & 42 \\
ROS1 & NM_002944 & Increase of & CN=6 & - & - & $91 \%$ \\
Copy number & - & - & & & & \\
\hline
\end{tabular}

PTCH, patched; ROS, receptor tyrosine kinase.
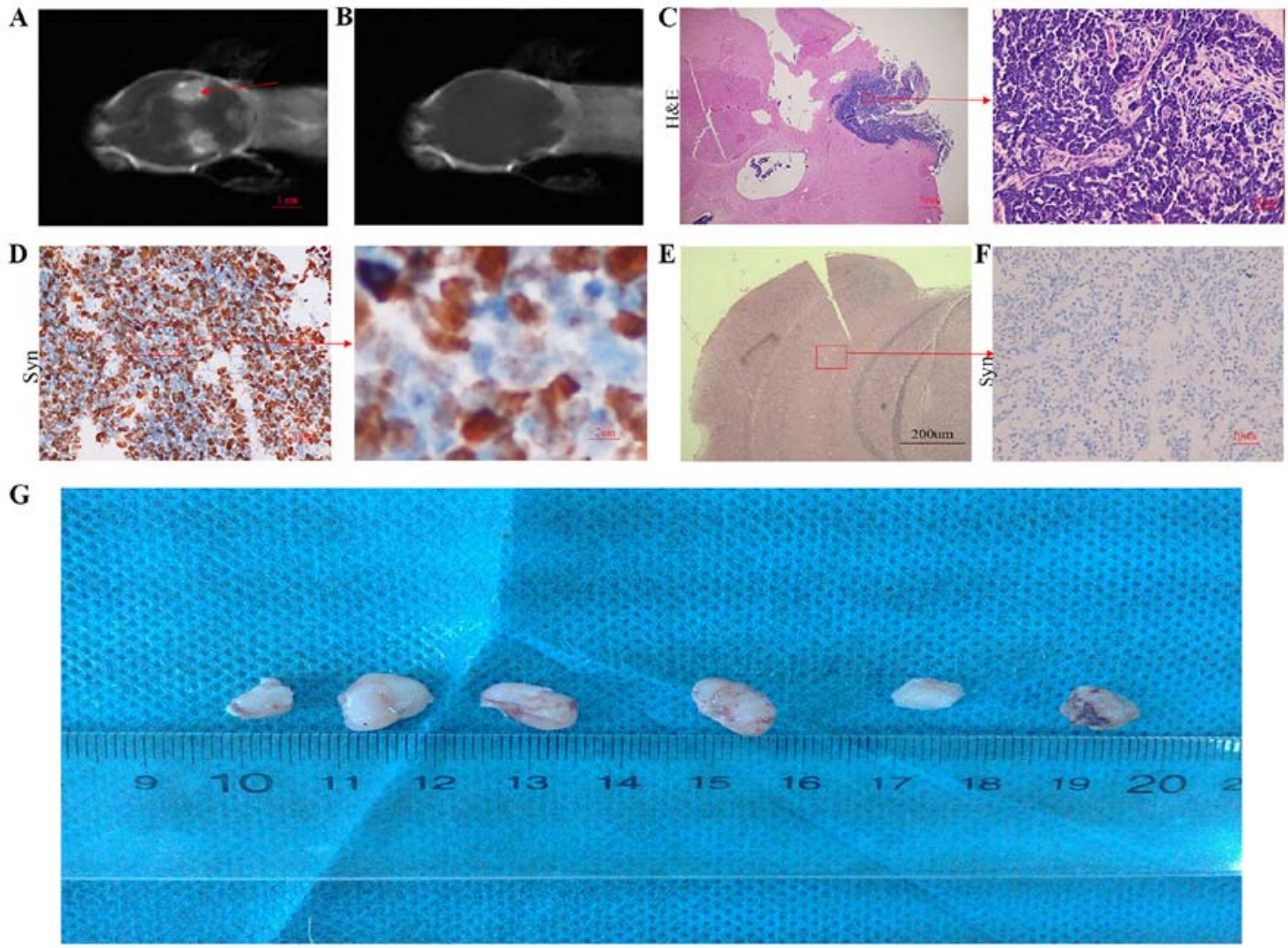

Figure 3. Imaging and pathological manifestations of intracranial and subcutaneous tumors in nude mice. (A) MR revealed the formation of intracranial tumor in nude mice. The arrows shows the location of the tumor. (B) The MR of the control animal showed that there was no tumor. (C) H\&E staining showed the formation of a medulloblastoma in the brain of the nude mice. (D) IHC showed Syn(+) cells in the tumor specimen from the intracranial tumor SCID mice. (E) The H\&E staining of the control group showed that there was no tumor in the injection position. (F) IHC of the control group presented as Syn(-). (G) The subcutaneous tumors formed in the SCID mice. IHC, immunohistochemistry; MR, magnetic resonance; Syn, Synaptophysin. 
Table III. Information of the targeted drugs which may be of use for treating the MB.

\begin{tabular}{|c|c|c|c|c|c|}
\hline Drugs & Clinical trial title & $\begin{array}{l}\text { Testing } \\
\text { stage }\end{array}$ & $\begin{array}{l}\text { Gene mutation } \\
\text { type and tumor type }\end{array}$ & NCT ID & State \\
\hline Sonidegib & $\begin{array}{l}\text { Molecular phase II study } \\
\text { to link targeted therapy to patients } \\
\text { with pathway activated tumors: } \\
\text { Module- } 5 \text { LDE } 225 \text { for patients } \\
\text { with PTCH1 or SMO mutated tumors }\end{array}$ & II & $\begin{array}{l}\text { Solid tumor and blood } \\
\text { tumor with PTCH1 } \\
\text { or SMO mutation }\end{array}$ & NCT02002689 & Completed \\
\hline $\begin{array}{l}\text { Vismodegib and } \\
\text { temozolomide }\end{array}$ & $\begin{array}{l}\text { An international, Randomized } \\
\text { open label phase I/II study } \\
\text { of Vismodegib in combination with } \\
\text { temozolomide versus temozolomide } \\
\text { alone in adult patients with recurrent or } \\
\text { refractory medulloblastomas presenting } \\
\text { an activation of the SHH pathway }\end{array}$ & II & $\begin{array}{l}\text { MB with } \mathrm{SHH} \\
\text { pathway activation }\end{array}$ & NCT01601184 & $\begin{array}{l}\text { In the } \\
\text { recruitment }\end{array}$ \\
\hline Vismodegib & $\begin{array}{l}\text { A phase II clinical trial evaluating the } \\
\text { efficacy and safety of GDC-0 } 499 \\
\text { in children with recurrent or } \\
\text { refractory medulloblastomas }\end{array}$ & II & $\begin{array}{l}\text { Recurrent MB with SHH } \\
\text { pathway activated } \\
\text { or inactivated }\end{array}$ & NCT01239316 & Completed \\
\hline BMS-833923 & $\begin{array}{l}\text { A phase Ib multiple ascending } \\
\text { dose study of BMS- } 833923 \\
\text { alone or in combination with } \\
\text { lenalidomide plus dexamethasone } \\
\text { or in combination with bortezomib }\end{array}$ & $\mathrm{Ib}$ & $\begin{array}{l}\text { Multiple progressive } \\
\text { tumors }\end{array}$ & NCT00884546 & Completed \\
\hline
\end{tabular}

Summary of drug information from the relevant clinical trials. MB, medulloblastoma; SHH, Sonic Hedgehog.

\section{Discussion}

Previously, clinicians have developed comprehensive treatment plans and predicted recurrence and metastasis risk for patients with MB according to the pathological type (16). Despite these classifications, patients from the high risk group who received identical treatment regimens have presented with varied prognoses. Therefore, the use of only the pathological classification does not meet the current treatment request. With the progress of genomics, MB has been found to be a type of brain tumor which present with varied molecular characteristics (17). It is now clear that MB is not a single disease entity, but instead consists of at least four distinct molecular subgroups: WNT/Wingless, SHH, Group 3 and Group $4(18,19)$. The heterogeneity within the same molecular subgroup has led to the identification of 12 subtypes within the current molecular subgroups, demonstrating the requirement to better characterize the specific driving factors that contribute to the subgroup heterogeneity (19). With the appearance of molecular classification, molecular targeted therapy has been expected to be more effective for the treatment of MB. Although there may be treatments that work on multiple forms of $\mathrm{MB}$, the diversity of the genetic and epigenetic events even within a particular subgroup, makes it likely that each patient will be responsive to distinct therapies and combinations thereof (20). Identifying appropriate therapies for each patient may require detailed molecular and cellular analysis of tumor tissues (20). At present, drugs which target the signaling pathways behind MB, such as the AKT pathway, SHH pathway and NOTCH pathway are already in clinical trials (21). Some of these targeted drugs have been proven to be ineffective in the clinical trials, while others have presented a significant influence on the prognosis, even within the same molecular subtype of MB (22). These results indicate that there are still significant deficiencies in the selection of targeted drugs based on the present MB molecular classification, making the selection of the appropriate treatment for patients with MB, unclear. In a previous study which investigated other types of malignant human tumors, it was proposed that individualized targeted therapies could be developed based on tumor driver genes which was considered as the main reference index for treatment (11). This may provide a new method to improve the effect of targeted therapies for the treatment for MB. A new study performed by the Children's Hospital of Philadelphia (USA) found that PF-06463922 targets the tumor driver gene, anaplastic lymphoma (ALK), in lung cancer and is effective for treating Neuroblastomas with ALK mutations (21). These results provide confidence that by analyzing the tumor driver genes from various patients with $\mathrm{MB}$, it will be possible to the best targeted drugs which have been used for the treatment of other tumor types.

In conclusion, the present study analyzed tumor driver genes from the tumor tissue collected from one patient with MB and screened for targeted drugs of the tumor driver genes. An intracranial and subcutaneous implanted models of MB were also 
developed in mice. The subcutaneous implanted model of MB may be of use for the preliminary screening of drugs for the treatment of MB. Due to the differences in the microenvironment between subcutaneous and intracranial tumors, further drug screening requires intracranial tumor models. Subsequent experiments could then validate the findings on the effects of these targeted drugs in an animal model of MB. Further experiments should investigate the characteristics of tumor driver genes in patients with different molecular subtypes.

\section{Acknowledgements}

Not applicable.

\section{Funding}

The study was supported by Science and education program of Suzhou (grant no. KJXW2017023).

\section{Availability of data and materials}

The datasets used and/or anlayzed during the present study are available from the corresponding author on reasonable request.

\section{Authors' contributions}

HW designed the study. YH performed the experiments. MC analyzed and interpreted the data and edited the manuscript. All authors read and approved the manuscript.

\section{Ethics approval and consent to participate}

All methods were carried out in accordance with guidelines and regulations of Soochow University. The human sample was used in accordance with the policies of the institutional review board of Children's Hospital of Soochow University. The use of the sample from the MB patient was approved by his parents. The study was approved by medical ethics committee of Children's Hospital of Soochow University.

\section{Patient consent for publication}

Written informed consent obtained from patient's parents prior to publication.

\section{Competing interests}

The authors declare that they have no competing interests.

\section{References}

1. Kumar R, Liu AP and Northcott PA: Medulloblastoma genomics in the modern molecular era. Brain Pathol 30: 679-690, 2020.

2. Dhall G, O'Neil SH, Ji L, Haley K, Whitaker AM, Nelson MD, Gilles F, Gardner SL, Allen JC, Cornelius AS, et al: Excellent outcome of young children with nodular desmoplastic medulloblastoma treated on 'Head Start' III: A multi-institutional, prospective clinical trial. Neuro Oncol: Apr 18, 2020 (Epub ahead of print). doi: 10.1093/neuonc/noaa102.
3. Batora NV, Sturm D, Jones DT, Kool M, Pfister SM and Northcott PA: Transitioning from genotypes to epigenotypes: Why the time has come for medulloblastoma epigenomics. Neuroscience 264: 171-185, 2014.

4. Ris MD, Packer R, Goldwein J, Jones-Wallace D and Boyett JM: Intellectual outcome after reduced-dose radiation therapy plus adjuvant chemotherapy for medulloblastoma: A Children's Cancer Group study. J Clin Oncol 19: 3470-3476, 2001.

5. Xu W, Janss A, Packer RJ, Phillips P, Goldwein J and Moshang T Jr: Endocrine outcome in children with medulloblastoma treated with 18 Gy of craniospinal radiation therapy. Neuro Oncol 6: 113-118, 2004.

6. Hoppe-Hirsch E, Renier D, Lellouch-Tubiana A, Sainte-Rose C Pierre-Kahn A and Hirsch JF: Medulloblastoma in childhood: Progressive intellectual deterioration. Childs Nerv Syst 6: 60-65, 1990.

7. Chen P, Fan Y, Man TK, Hung YS, Lau CC and Wong ST: A gene signature based method for identifying subtypes and subtype-specific drivers in cancer with an application to medulloblastoma. BMC Bioinformatics 14 (Suppl 18): S1, 2013.

8. Perou CM, Sørlie T, Eisen MB, van de Rijn M, Jeffrey SS, Rees CA, Pollack JR, Ross DT, Johnsen H, Akslen LA, et al: Molecular portraits of human breast tumours. Nature 406: 747-752, 2000

9. Sanai N: Integrated genomic analysis identifies clinically relevant subtypes of glioblastoma. World Neurosurg 74: 4-5, 2010.

10. Kool M, Koster J, Bunt J, Hasselt NE, Lakeman A, van Sluis P, Troost D, Meeteren NS, Caron HN, Cloos J, et al: Integrated genomics identifies five medulloblastoma subtypes with distinct genetic profiles, pathway signatures and clinicopathological features. PLoS One 3: e3088, 2008.

11. Yang J, Wang X, Kim M, Xie Y and Xiao G: Detection of candidate tumor driver genes using a fully integrated Bayesian approach. Stat Med 33: 1784-1800, 2014

12. Vogelstein B, Papadopoulos N, Velculescu VE, Zhou S, Diaz LA Jr and Kinzler KW: Cancer genome landscapes. Science 339: 1546-1558, 2013.

13. Ohshima K, Hatakeyama K, Nagashima T, Watanabe Y, Kanto K, Doi Y, Ide T, Shimoda Y, Tanabe T, Ohnami S, et al: Integrated analysis of gene expression and copy number identified potential cancer driver genes with amplification-dependent overexpression in 1,454 solid tumors. Sci Rep 7: 641, 2017.

14. Akavia UD, Litvin O, Kim J, Sanchez-Garcia F, Kotliar D, Causton HC, Pochanard P, Mozes E, Garraway LA and Pe'er D: An integrated approach to uncover drivers of cancer. Cell 143: 1005-1017, 2010.

15. Son EI, Kim IM, Kim DW, Yim MB, Kang YN, Lee SS, Kwon KY, Suh SI, Kwon TK, Lee JJ, et al: Immunohistochemical analysis for histopathological subtypes in pediatric medulloblastomas. Pathol Int 53: 67-73, 2003.

16. Aref D and Croul S: Medulloblastoma: Recurrence and metastasis. CNS Oncol 2: 377-385, 2013.

17. Kijima N and Kanemura Y: Molecular Classification of Medulloblastoma. Neurol Med Chir (Tokyo) 56: 687-697, 2016.

18. Gottardo NG, Hansford JR, McGlade JP, Alvaro F, Ashley DM, Bailey S, Baker DL, Bourdeaut F, Cho YJ, Clay M, et al: Medulloblastoma Down Under 2013: A report from the third annual meeting of the International Medulloblastoma Working Group. Acta Neuropathol 127: 189-201, 2014.

19. Ferrucci V, de Antonellis P, Pennino FP, Asadzadeh F, Virgilio A, Montanaro D, Galeone A, Boffa I, Pisano I, Scognamiglio I, et al: Metastatic group 3 medulloblastoma is driven by PRUNE1 targeting NME1-TGF- $\beta$-OTX2-SNAIL via PTEN inhibition. Brain 141: 1300-1319, 2018.

20. Wang J, Garancher A, Ramaswamy V and Wechsler-Reya RJ: Medulloblastoma: From molecular subgroups to molecular targeted therapies. Annu Rev Neurosci 41: 207-232, 2018.

21. Mackall CL: In search of targeted therapies for childhood cancer. Front Oncol 1: 18, 2011

22. Kumar V, Kumar V, McGuire T, Coulter DW, Sharp JG and Mahato RI: Challenges and recent advances in medulloblastoma therapy. Trends Pharmacol Sci 38: 1061-1084, 2017.

(i) () $९$ This work is licensed under a Creative Commons Attribution-NonCommercial-NoDerivatives 4.0 International (CC BY-NC-ND 4.0) License. 